\title{
Application of corporate Social Responsibility in Stakeholder Management: The Case of Langkawi, Malaysia
}

\author{
Azilah Kasim ${ }^{1}$, Nor Azman Yussuf ${ }^{2}$, Chansoo Park ${ }^{3}$ \\ ${ }^{1}$ Universiti Utara Malaysia, Malaysia \\ ${ }^{2}$ Langkawi Development Authority, Malaysia \\ ${ }^{3}$ Memorial University of Newfoundland, Canada
}

\begin{abstract}
The continued growth of tourism has driven the Malaysian government to focus on various developments and promotional activities to expand the industry. However, these efforts more often than not failed due to the failure of government arms to adopt an inclusive management approach on tourism stakeholders. A destination management organization (DMO) often behaves in manners typical of a government agency. Such approach often brings problems such as communication barriers and bureaucracy between a DMO and its stakeholders. Thus, government arms need to change their management approach by adopting a more stakeholder-friendly approach offered through the corporate social responsibility (CSR) concept. As the support of stakeholders is crucial for a destination's development and sustainability, this paper applies the concept of CSR in destination management by proposing the need for a DMO to adopt an approach similar to CSR if they were to operate more effectively. It uses a case study on Langkawi's DMO in Malaysia called the Langkawi Development Authority (LADA). Using documented evidence and in-depth interviews, the challenges that LADA face in getting stakeholder support are explored. The paper then outlines how, and justifies why a DMO can adopt CSR approach to mitigate the complexity it faces in dealing with its stakeholders.
\end{abstract}

Keywords: Destination management organization, stakeholder engagement, sustainable tourism development.

\section{INTRODUCTION}

The tourism industry is a significant economic contributor to many countries. In Malaysia, the tourism sector ranks as a second generator of income with tourist arrivals growing by four times from 23.65 million in 2009 (Bernama, 2010) to 25.03 million in 2012, with tourist receipts of RM65.44 billion received in 2013 (Tourism Malaysia website, 2014). The continued growth has driven the Malaysian government to focus on various developments and promotional activities to expand the industry. In Malaysia Plan 10 (MP10, 2011-2015), nine core areas of tourism development will be the focus. These are eco-tourism, heritage tourism, homestay tourism, coastal and island tourism, sports tourism, meetings and exhibition tourism, golf tourism, food tourism, shopping, and health tourism (see Anuar, Ahmad, Jusoh, and Hussain, 2013). Major events such as the Malaysia International Shoes Festival, Formula 1 and Motor GP etc. will also be organized to attract local and international tourists. Other plans to encourage tourism growth include nationwide programmes for safety, cleanliness, comfort, and facilities improvement. In short, tourism is a prioritized industry and a significant contributor to national income, creating jobs and more economic growth to the country. According to a report from the Performance Management and Delivery Unit (PEMANDU, 2012) Malaysia aims to have 36 million tourist arrivals and RM168 billion receipts by 2020. Arrivals of tourists in big numbers, and all tourists' activities, will no doubt generate economic, social, and environmental impacts.

However, impacts can be both positive and negative. Achieving sustainable tourism development requires constant monitoring of impacts and introduction of essential preventive or corrective actions whenever needed. Therefore, impact management is important in order to maximize the positives and minimize the negatives. Such effort needs the participation of all relevant stakeholders, as well as strong political leadership to ensure wide involvement and agreement structure. Thus, collaboration and engagement of all stakeholders is required for overall success of tourism. To create this engagement, stakeholder management practices should be used as a key to create strong relationships between the tourism organizations and their stakeholders. 
Positive impacts that could lead to a more sustainable tourism industry is particularly important in Langkawi as the island is bursting with beautiful natural resources that form its crucial attractions. Langkawi is located in the northeast of the peninsular and consists of 99 beautiful islands that are of archaeological importance. Langkawi's main economy is tourism related and most of the residents either run or are employed in tourism and hospitality related businesses. Tourist arrival in Langkawi has been increasing, and this is particularly observable since Thailand's 2010 political turmoil. The higher arrival has led to higher demand for accommodations and other tourism related businesses (Kasim and Dzakiria, 2015). It also led to the decision to build newer products such as the Water Theme Park, Butterfly Park, and the New Marine Park to attract tourists.

The abundance of naturally beautiful sceneries, the vernacular houses and kampungs, the rivers and mountains, the tropical rainforests and mangroves, the natural lakes, the sandy beautiful beaches, the crystal clear sea and coral reefs coupled with the diverse historical and cultural heritage (Tourism Malaysia website, 2014) make Langkawi more attractive as a nature based tourism destination. High ease of tourist access through air and sea routes to the island from local and international points of origin is another contributing factor to the rapid growth of tourism on the island. Travelling via road within the island does not take more than 45 minutes to reach one end of the main island from the other. For visiting the attractive tourist places in some of the small islands, tourists will need to take a boat tour or a private boat rental. If tourists have difficulty finding their destinations, they can go to the nearest tourist information centre located throughout Langkawi. With good connectivity with major airports such as KLIA, LCCT, Subang Sky Park, Penang International Airport, and Changi International Airport, Langkawi is now a year round tourism destination. Beside flights, good ferry services from Kuala Kedah, Kuala Perlis, Penang and Satun in Southern Thailand also help make Langkawi a year round destination. The introduction of more international flights such as MALINDO and AIR ASIA $X$ to the island has improved air access to the island as well.

Langkawi Island was economically flagging when agriculture was its primary economic activity because the island was and is still too small to produce significant agricultural output. Low paddy yield worsened due to the lack of irrigation facilities and the use of traditional methods of agriculture. However, the declaration of a "Duty Free Island" in 1987 has provided the island with a profitable commercial sector and changed its socio-economic development pattern. By the mid-1990s, the service sector became a key contributor to the economy of the island (Langkawi Municipal Council, 2002). Only $17.3 \%$ of the island's population still engage in agricultural and fisheries related work at this time (Langkawi Municipal Council, 2002). Tourism sector jobs increased people's wage from RM500 up to RM2000 a month (Langkawi Municipal Council, 2002; LADA, 1999). The tourism industry progress has also changed the migration patterns of young people from the island to the mainland of Malaysia. The migration pattern of youngsters out of Langkawi made a significant turnaround due to job availability on the island (LADA Annual Report, 2013). Positive acceptance of local people towards tourism may also be due to an increase in the basic infrastructure and public facilities on the island (Marzuki, 2008). In short, tourism development in Langkawi has turned the island from a sleepy fishermen island to one of the most popular island tourism destination in Southeast Asia, if not the world. It clearly manifests the impact of tourism on a flagging economy's revitalization because it has managed to generate employment, enhance community infrastructure, and enhance the development of related industries such as accommodation, transportation, leisure, services and hospitality on the island.

However, the growth didn't come without costs. Hence, Langkawi's destination managers need to adopt sustainability in every aspects of management to address those costs. This requires good partnership and collaboration between LADA and other agencies (governmental, business, local community etc.) to understand and try to overcome the complexities involved so that potential solutions can be formulated. Since the tourism industry is fragmented in nature, it is hard for any one entity to succeed in isolation. Therefore, involving a wide variety of types and size of public, private and not-for-profit entities is an important strategy. In this paper, the complexity of tourism stakeholder management in the context of an island tourism destination is presented. It begins with a literature review of the CSR concept followed by the qualitative data on stakeholder management complexity that LADA faces. Then it outlines the importance of adopting the CSR approach as a possible solution to the issue because it believes that when a DMO thinks more like a business rather than just a country's administrative arm, it can benefit from the values mooted in CSR. It also recommends several initiatives that a DMO can take in managing stakeholders using a CSR approach. 


\section{LITERATURE REVIEW}

According to the International Finance Corporation (IFC) handbook in 2007, stakeholders are individuals or groups who are involved directly or indirectly with the project, as well as those who might have benefited from the project or their ability to influence a project's outcome, whether positive or negative. Stakeholders may contain local host communities or individual hosts, official and unofficial representatives, local authority or national government, politicians, religious leaders, civil society organizations, special interest groups, the academic community, or other businesses. For Yilmaz and Gunel (2009), the term "stakeholder" refers to the numerous interests from those who participate in a business. They also mention that organization stakeholders can be divided into primary stakeholders and secondary stakeholders depending on the business's set of expectations, needs, and values.

Deegan (2002) posits that corporations are involved in CSR practices for several reasons, such as to abide with legal requirements, to be more accountable and responsible towards stakeholders, to satisfy with community expectation, to legalize activities and behaviour towards the stakeholders and/or to attract in investment funds in to have more competitive advantages (Yusniyati Yusri and Azlan Amran, 2012). According to Suchman (1995); Orr and Scott (2008); Veleva (2010); Bagire et al. (2011), corporations must satisfy the expectations of stakeholders in order for the corporation to develop a positive corporate image (Monowar Mahmood and Humphrey, 2013). Hess and Warren (2008) also state that a corporation's reputation will improve if the expectations of the stakeholders involved were met with the concern of CSR (Brown, 2014). Besides that, according to Yang and Rivers (2009); Cruz and Boehe (2010), the corporation's CSR activities should incorporate stakeholders' expectations in order for the organization to gain competitive advantage (Monowar Mahmood and Humphrey, 2013). However, according to Velasquez (1988), corporations will experience higher chances of losing their reputations, their sales, and their profits if they do not meet all stakeholders' expectations (Stoian and Zaharia, 2012).

As a sustainable tourism development approach requires greater involvement of stakeholders in decision-making particularly through the formation of partnerships, (Maiden, 2008), stakeholder engagement is very important in achieving organizational success. Without collaboration, small- and medium-sized tourism enterprises (SMTEs) will not be able to maintain their competitiveness (Tuohino and Konu, 2014). Decentralized decision-making and authorization of community has proven to be a powerful factor in ensuring a bottom-up development of an island, and cooperation between stakeholders in the host community can ensure the development of institutions to reduce the potential negative aspects of tourism growth and to maximize the benefits to society (Johnsen, 2013). Even though the necessity for successful and strategic affiliations between an organization and its stakeholders is mentioned frequently for the tourism sector, there is still inadequacy in its implementation. For overall success of tourism, stakeholder management practices should be used as a key to build solid relationships between the tourism organizations and their stakeholders (Yilmaz and Gunel, 2009).

Additionally, stakeholders are contributory to accomplishing sustainability objectives. Hence their views are fundamental for the development of effective stakeholder engagement strategies. An early theorist on collaboration i.e. Gray (1989) proposed that "collaboration is a process of join decision making among key stakeholders of a problem domain about the future of that domain" (p.225). To Gray, inter-organizational collaboration theory offers strong possibility for managing issues at destination level, provided the basic pillars of collaboration are understood. Those pillars are: 1) that stakeholders are independent, 2) that solutions emerge by dealing constructively with differences, 3) that joint ownership of decisions is involved, 4) that the stakeholders assume collective responsibility of the on-going direction of the domain, and 5) that collaboration is an emergent process. Meanwhile Waligo, Victoria, Clarke, Jackie, Hawkins, and Rebecca (2013) contend that the key driver factors influencing stakeholder engagement in sustainability of tourism development were 1) leadership quality, 2) information quality and accessibility, 3) stakeholders' mindset, 4) stakeholder involvement capacity, 5) stakeholder relationships and 6) implementation priorities. While both old and new theory seems to propose different things, there is a clear logic between what they proposed. For example, 
information quality and accessibility, stakeholders' mindset, and involvement capacity will determine whether issues are being dealt with constructively, and whether there will be joint ownership of decisions and shared responsibility of the on-going direction of the domain.

Stakeholder's mindset and involvement capacity relate to how empowered they feel towards the issue at hand. According to Abdullah, Hassan, Ali, and Ab. Karim (2014), a low power distance among stakeholders can avoid conflicts and misunderstandings, and encourage better power relations with more capability to access information, and provide greater willingness to share information. They also mentioned that it will help to promote a transparent managing and organizing process for mega-events by using honest worthy power relation among stakeholders who takes into account the hosts of destination opinions, views and comments. Low power distance can motivate stakeholders to get involved. The motivation, the selection and enrolment of stakeholders are essential for the success of a collaborative project (Jakše and Ambrož, 2015) because they legitimize the project and encourage the use of innovative potential. Managing the engagement with each stakeholder should likewise pay attention to the organizational actions and initiatives, with the goal of creating, building and strengthening the organization's bonds with each respective stakeholder (Mainardes, Alves, and Raposo, 2012).

In the tourism literature, collaboration and engagement have received considerably low attention. With this in mind, this case study intends to contribute to knowledge on the topic by assessing the managerial challenges in engaging the stakeholders in making Langkawi a sustainable tourism destination. Sustainable tourism is a concept already adopted by many destinations such as Costa Rica, and Maldives to counter or minimize negative impacts often associated with the practice of mass tourism. It opens door for management of existing tourism resources for the benefit of future generations. It advocates that destination or tourism products managers strive to incorporate sustainable practices into their management style. However, incorporating sustainable tourism requires strong collaborative vision, planning and strategies pre-empted between destination managers and the relevant stakeholders. It should begin with an awareness and understanding on the concept itself, and readiness to launch the concept into practice.

\section{THE CASE STUDY}

Collaboration, specifically through multi-stakeholder partnerships, is an effective way to support initiatives in tourism development. Informal and formal collaboration, cooperation and partnerships among relevant parties are vital to the success of sustainable tourism implementation at a given destination. This case study focuses on the island's destination management organization's (DMO) effort to engage with its stakeholders and the managerial challenges that it faced particularly in forming a collaborative effort towards making Langkawi a sustainable tourism destination. It provides the context, the players and the managerial challenges of collaborating with stakeholders in the context of an island tourism destination.

\subsection{Research Methodology}

The methodology for this case study involves a combination of secondary and primary data. The secondary data collection relies on contemporary literature, documents and projects connected to the stakeholder theory, stakeholder's engagement, management and collaboration in tourism development of Langkawi. The primary data consists on interviews with representatives of LADA in order to get more detailed information and to create a clear picture about LADA's function in engagement and collaboration with the stakeholders of Langkawi tourism. Interviews were conducted with a number of diverse but relevant stakeholders to provide a multidimensional perspective on the issue. The total number of informants involved in this study was nine.

\subsection{Findings}

The DMO in Langkawi is called Langkawi Development Authority (LADA). It was mandated to plan, promote and implement development on the island of Langkawi. LADA was officially established on March 15, 1990 under the Langkawi Development Authority Act 1990 (Act 423) and placed under the authority of the Ministry of Finance. Headed by Tan Sri Khalid Bin Ramli as the Chief Executive Officer (CEO) LADA carries four main objectives, namely to ensure Langkawi will become a tourist 
destination and investment selected, to ensure infra-tourism impact and outcome exercised provides targeted and value for money, to ensure every irresistible spent provision return to community development Langkawi particularly to the Nation and to ensure customer satisfaction and stakeholders in level of excellence. LADA's vision is to be a lead agency for development in Langkawi to be a premier world-class tourism island destination. Their mission statement is to the implementation of the tourism industry progressing Langkawi the benefit of the community, state and nation through the strategic planning and effective governance. As stipulated in Act 423, LADA has four functions, firstly, to encourage, stimulate, accelerate and implement socio-economic development in Langkawi, secondly to promote the entire Langkawi region as a duty- free tourist destination, thirdly to promote, stimulate and implement tourism and infrastructure policy, as well as the residential, agricultural, industrial and trade developments in Langkawi and lastly to coordinate the abovementioned developmental activities in Langkawi.

Based on Act 432, LADA has the mandate and trust of the Federal Government to implement developmental activities in line with three policies. The first one is to coordinate all activities involving tourism, business or industrial development, second is to work in full cooperation with any third parties involved with such activities and the third policy is to lend financial or other types of assistance to any third party with the proven ability to undertake tourism, business or industrial developments authorized by LADA. Clients' Charter in LADA to be understood and carried by all responsible is they promise to promote, encourage and facilitate the economic and social development of Langkawi as a premier tourism island destination with a unique duty-free status in the region. The goal of LADA's Tourism Division has always been to catapult Langkawi into the premier eco-tourism island destination, and to be one of the best and most unique travel destinations in the world. As the only Southeast Asian destination to attain UNESCO's highly coveted Global Geopark status, LADA now has the leverage to highlight Langkawi's spectacular natural attractions via the growing industry niche of eco-tourism.

Resource wise there are a total number of 104 islands in the Langkawi archipelago. The main attraction is the UNESCO certified Langkawi Geopark which has three amazingly unique geoforest parks in it. The first is the Matchinchang Cambrian Geoforest Park which is estimated 450 to 550 million years old which contains the oldest known rocks in the region and is evidence that the geological origins of Malaysia and even all of Southeast Asia may have begun here. The second is The Kilim Karst Geoforest Park, which is also known as a world-class nature attraction featuring a gorgeous limestone landscape, an extensive mangrove forest system, lovely beaches, coastal wetlands and two islands (Langgun and Dendang) that are spectacular nature parks in themselves.

The third is Dayang Bunting Geoforest Park on Dayang Bunting Island that known as the setting for one of Langkawi's most famous natural attractions. The collapse of an ancient cave system formed the beautiful lake. The Pasir Dagang Cave is one of the beautiful marble caves abound on the island. The marble mined on the island is among the best in the world and can only be accessed with proper caving equipment but the payoff at the end is a magical cavern filled with spectacular curtain stalactites and a gigantic limestone chandelier. Langkawi Geopark is the only Geopark that is an archipelago, or island cluster with over 90 geological sites around the Geopark that are under research and have been shown to possess high heritage value. It is also the world's first duty-free Geopark. The whole region possesses an abundance of geological attractions like caves, sea arches and stacks, fossils, glacial drop stones and cascading waterfalls. Culturally, the fact that the people of Langkawi have been isolated from the mainland helped them develop a very rich legacy of myths and legends that blend in with the fascinating oral history of their colourful, if often violent, past.

Officially declared as a Geopark in 2006 and accepted as a member of UNESCO's prestigious Global Geoparks Network (GGN) in 2007, Langkawi Geoparks which brings with it an international validation and an edge. Apart from the Geopark, Langkawi also has the Laman Padi Rice Museum, a 14-acre Living Museum to preserve traditional paddy-farming techniques and to showcase the historical and cultural importance of traditional rice farming in the region. Air Hangat Village offers a hot spring spa and water therapy with natural mineral-laden waters. The Oriental Village provide grocery and souvenir shops, a Sustainable SME Research Centre, a Geopark Information Centre and 
other business activities related on tourism. There are also public recreational facilities such as football field and stadium, and facilities for popular sports like tennis, badminton, aerobics and martial arts.

\subsection{The DMO's Stakeholder Engagement Approaches}

To enable the tourism sector in Langkawi to attain sustainability, Langkawi's management should have clear targets, strategic planning and effective implementation among their stakeholders. The Langkawi Blueprint development was one of the governmental efforts to foster an effective collaboration between Federal and State agencies as well as between the public and private sector to enhance Langkawi development. With the joint commitment of all stakeholders, Langkawi's position on the world map can be secured and LADA vision of being a leader for development agency will be fulfilled. The blueprint is a comprehensive plan to make Langkawi among the world's best ten islands and eco-tourism destinations. It includes fourteen initiatives that have been designed to cover three themes i.e. the product, the infrastructure and the enablers (see Figure 1).

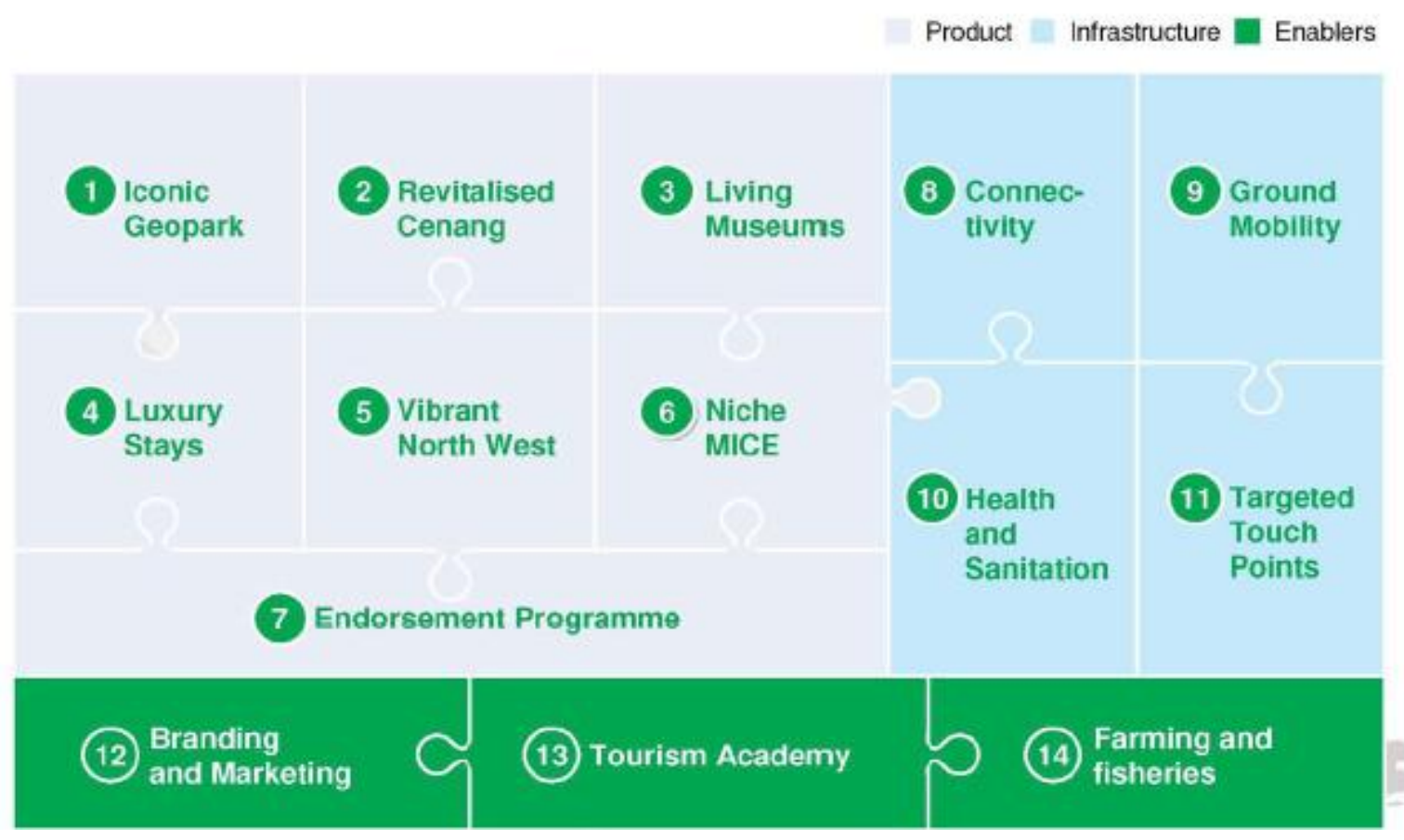

Figure1. Portfolio of 14 initiatives across 3 themes

Source: $L A D A, 2015$

LADA uses Langkawi Tourism Blueprint as an approach or guidelines in their engagement with the stakeholders. To ensure the effectiveness implementation of the Blueprint, the responsibility of monitoring was carried out by all stakeholders and coordinating agency based on mutually-agreed Key Performance Indicators (KPI). As of December 2013, all implementing agencies have successfully implemented initiatives accounted according to the schedule (LADA, 2013). Along with the multi-steps transformation and rapid changes occurring in the present era of government administration, organizational developments in LADA has continuously been streamlined towards improvement. To assist the development of a culture of excellence in the workplace, LADA has established Quality Management System (QMS) through the implementation of the MS ISO 9001: 2008, which encompasses the scope as follows (see Figure 2):

\section{MS:}


Application of corporate Social Responsibility in Stakeholder Management: The Case of Langkawi, Malaysia

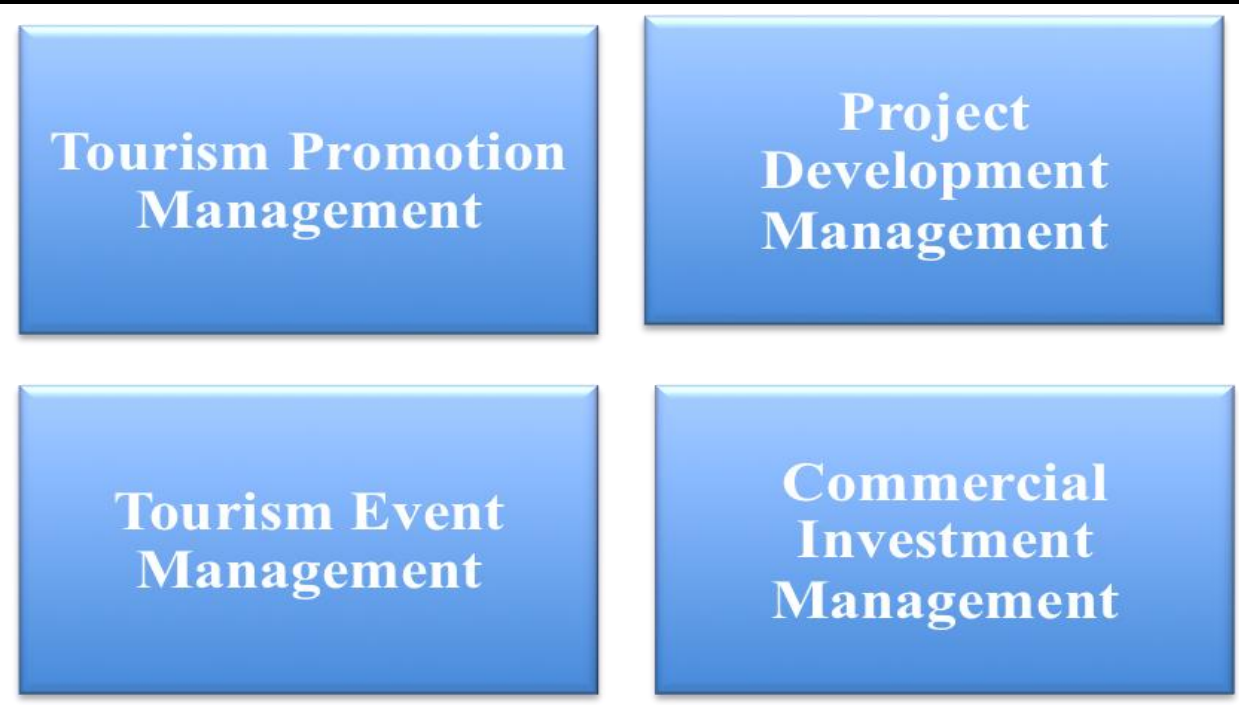

Figure2. Quality Management System (QMS)

Source: $L A D A, 2013$

As a strategic national economic transformation programme is considered the starting point towards the realization of a more sustainable tourism industry in Langkawi, LADA strives to meet the needs of the tourism industry's stakeholders and the challenges by supporting the implementation of the Blueprint Tourism Langkawi and making the island one of the 10 eco-tourism destinations in the world. The strategic plan was to focus on the following core Key Result Area (KRA):
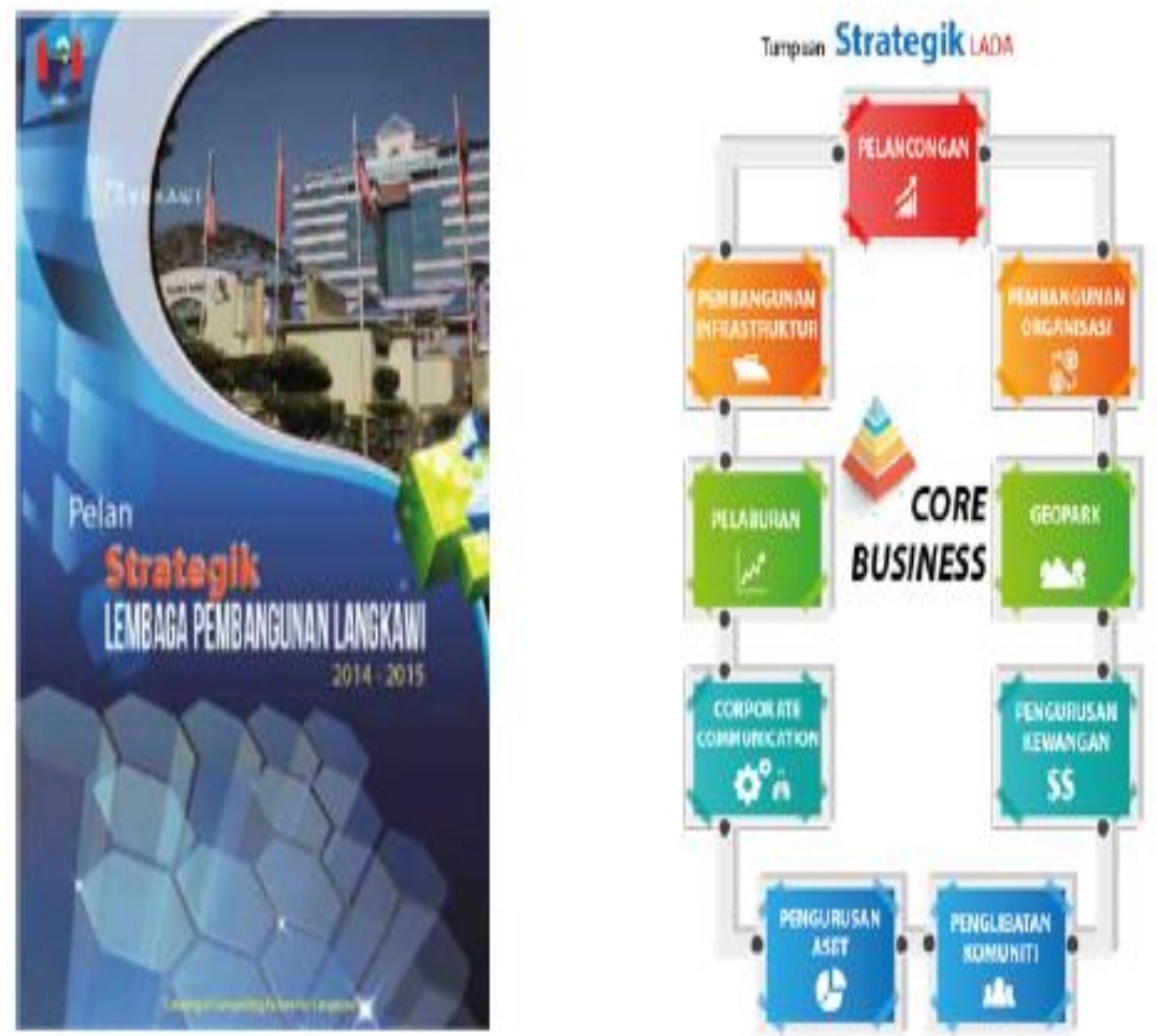

Figure3. Quality Management System (QMS)

Source: $L A D A, 2013$ 
For the community, LADA also attempts to ensure that tourism infrastructure and community amenities have a positive impact on the overall community development. This involves efforts and initiatives around Langkawi in collaboration with the Village Development and Security Committee (JKKK) and local communities and in line with this vision, the Strategic Plan Community Development to disclose the direction of a more comprehensive program to improve the socioeconomic condition of Langkawi. Projects and programs have been implemented by LADA such as My Community Naturally Langkawi, which held at Pasir Hitam and Sungai Menghulu and Program Outreach. These programs have a positive impact on both sides. Projects and programs provide numerous benefits to society as capable of improving the socio-economic income. In addition to the education sector to be addressed, the development of human capital can be seen through community participation in activities and projects. This is one of the approaches that LADA applies in order to build better engagement with the stakeholders.

The Geopark status of Langkawi gives LADA an obligation to ensure that the local community makes use of their traditional culture and knowledge in economically beneficial way through tourism. Local operators such as nature guides, boat operators, food vendors, artisans, cultural performers or souvenirs sellers are involved in offering products and services that comply with the Geopark guidelines. Fishermen and farmers promote or sell their 'lifestyle tours' (tours offering tourists to join their authentic daily activities or stay in homestays). This ensures that the local population get a wide variety of tourism-related jobs and business opportunities.

LADA also attempts to engage the stakeholders through its events. Engagement is based on three main principles i.e. planning, commitment and inclusiveness. It can take many forms: socio economic, human capital, infrastructure, events, management, industrial relations and tourism. One of the main reasons for organizing tourism events in Langkawi are to get participation from local community and give benefit to local economy (Table 1). The events allow the stakeholders to be involved by means of joining the organizing committee, being a volunteer, being part of the technical support team and running the aid stations.

Table1. Iconic Events in Langkawi for 2015

\begin{tabular}{|l|l|}
\hline Langkawi International Laksa Carnival (LILAC) & May \\
\hline Xterra Asian Championship & May \\
\hline Ironman Triathlon Malaysia Langkawi & September \\
\hline Asian Bird Fair & November \\
\hline Geopark Carnival & November \\
\hline ISAF World Youth Sailing & December \\
\hline FISE World Series & December \\
\hline
\end{tabular}

Source: $L A D A, 2015$

The most successful event involving local community was Ironman Malaysia Langkawi that was held in November 2015. It required 2000 manpower, which includes volunteers and technical support team. Local communities were given opportunities to manage 13 aid stations around the island on their own. All villagers have the chance to showcase their local culture, specialities, uniqueness and creativity to all ironman athletes and spectators. Engagement with local community began from identifying the race route stage until the execution of the events. As a result, the event gave wonderful experiences and memories to athletes participating in the events. Athletes gave good comments on local participation to the event. 'It was an amazing ironman triathlon with good venue, excellent organizer and wonderful local supporters' - Diana Riesler, PRO Women Champion. Feedback from the locals show that they look forward to the next edition of Ironman Malaysia Langkawi, which is scheduled to be on 12 November 2016.

The Geopark Carnival was a perfect platform for local community to showcase the uniqueness and diversity of their local culture to tourists. As the Geopark concept is about preserving natural heritage, community was invited to take part by exhibiting local product, demonstrating local craft, performing traditional music and dance, joining the event's committee and other interactive activities. Thailand and Indonesia were also invited as exhibitors to showcase their potential Geopark sites. It was a good platform for local community to do networking with regional friends, changing experiences, sharing knowledge and learning process. The local communities were given opportunities to earn incomes during events as food caterer, logistic contractor or supplier and 
Application of corporate Social Responsibility in Stakeholder Management: The Case of Langkawi, Malaysia

manpower provider. Examples of community development programmes that LADA organizes are in Table 2 while Figure 4 presents the economic development clusters of Langkawi. In the programmes specified, LADA emphasized the link between sustainable tourism practices and the continuity of community survival to those involved (Table 2 and Figure 4).

Table2. Community Development Programme

\begin{tabular}{|c|c|}
\hline 1. & $\begin{array}{l}\text { Entrepreneur Workshop } \\
\text { - } \text { Bakery } \\
\text { - } \text { Marine based product } \\
\text { - } \text { Art and Craft } \\
\text { - Chocolate }\end{array}$ \\
\hline 2. & Online Business Marketing \\
\hline 3. & Local Craft Workshop - Tuba Island \\
\hline 4. & Basic Financial Management and Business Planning \\
\hline 5. & Outreach Programme with Community -6 series as per Mukim \\
\hline 6. & $\begin{array}{l}\text { School Kids Motivational Programme } \\
\text { - Primary } \\
\text { - Secondary } \\
\text { - Tourism Academy }\end{array}$ \\
\hline 7. & Development of Business Portal \\
\hline 8. & $\begin{array}{l}\text { Basic Tour Guide Course } \\
\text { - Nature } \\
\text { - } \quad \text { Bird watching / Butterfly } \\
\text { - Geopark }\end{array}$ \\
\hline 9. & We Are The Host \\
\hline 10. & Think Tourism - I LOVE LANGKAWI \\
\hline 11. & $\begin{array}{l}\text { Business Opportunity in Tourism Industry } \\
\text { - Tourism related business }\end{array}$ \\
\hline 12. & $\begin{array}{l}\text { Sustainable Tourism in Aspect of Local Community } \\
\text { - Recycle } \\
\text { - Green practises }\end{array}$ \\
\hline 13. & Youth Entrepreneur Development Workshop \\
\hline 14. & MyNiaga Seminar \\
\hline
\end{tabular}
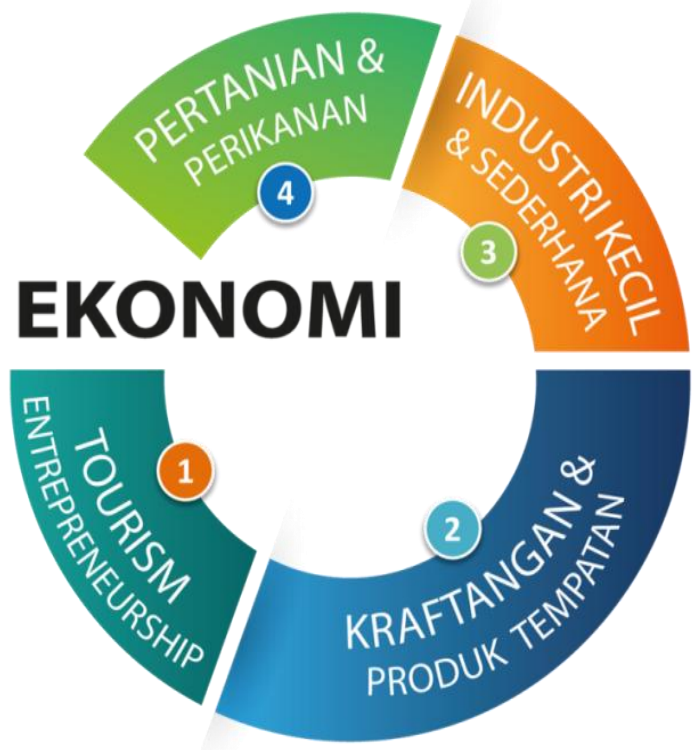

Figure4. Economic Development Cluster

Source: LADA Annual Report, 2013

Social development is another important element in the community development cluster. To achieve it, LADA focused on three main areas i.e. culture, religious and safety. Infrastructures development addresses issues of sanitation and cleanliness, basic facility and utilities (Figure 5 and Table 3). 


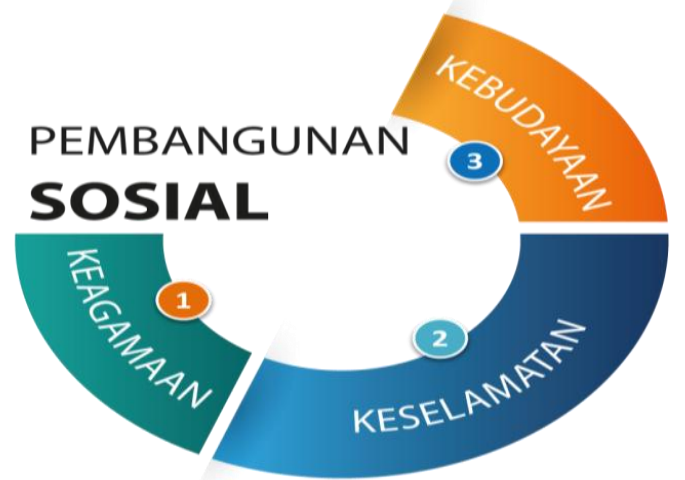

Figure5. Social Development Cluster (LADA Annual Report, 2013)

Table3. Infrastructure and Social Programme

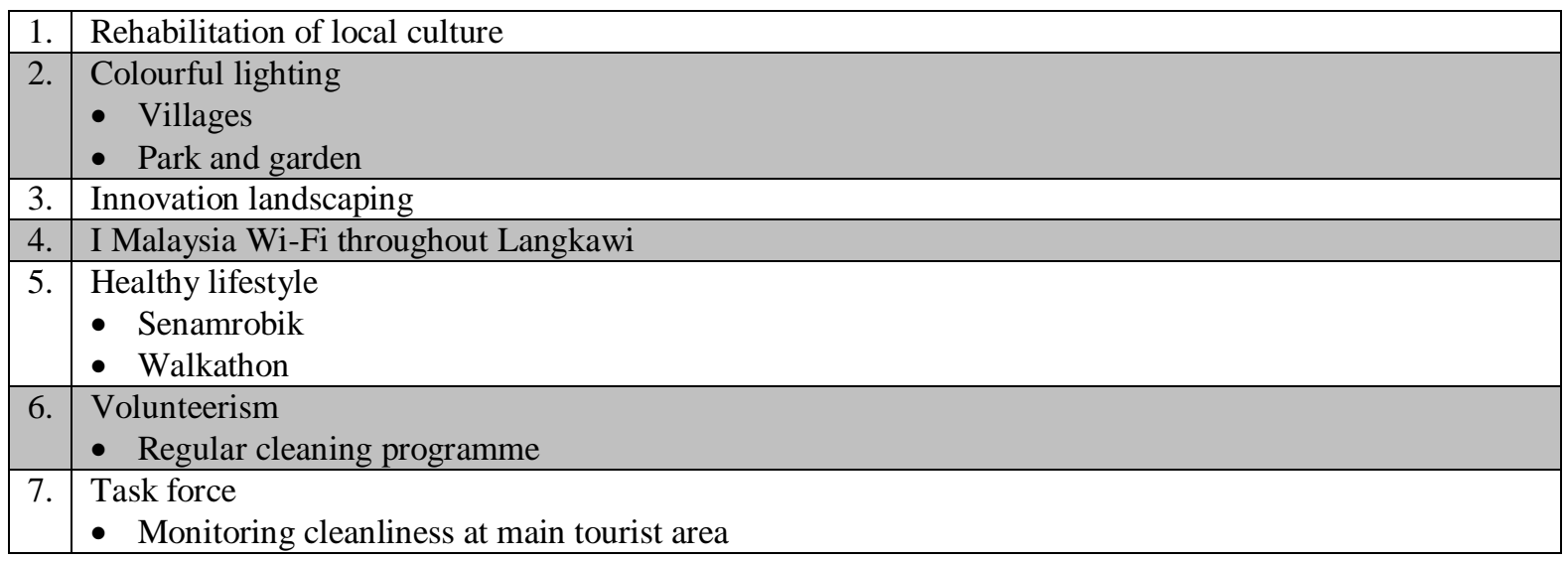

Source: $L A D A, 2015$

\section{Industry Relations:}

LADA believes in working with all government agencies such as the District Office, Langkawi Municipal Council, the Forestry Department, Department of Environment and private tourism agencies in its community engagement. Such collaboration also boost relations with those agencies and other important stakeholders such as hoteliers, tour operators, product operators, restaurant operators, tour guide, retailers, taxi drivers and other tourism related players. A yearly programme has been implemented by LADA to engage with local industry players on issues and challenges facing by tourism industry (Table 4).

Table4. Programme with Industry Players

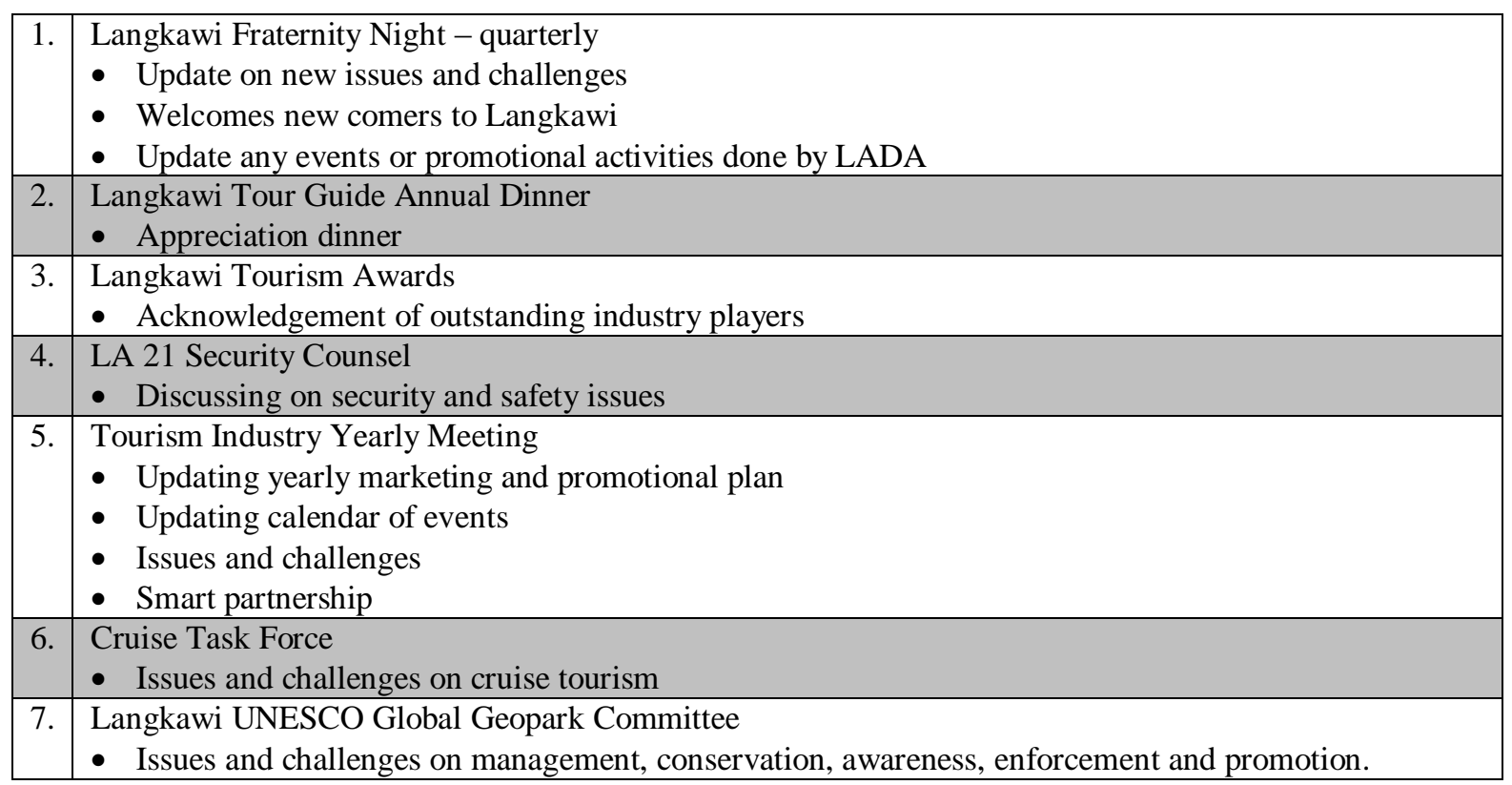

Source: $L A D A, 2015$ 
Of course all these initiatives do not come with challenges. Due to limited power and resource, engaging with the industry can be a complex task that LADA has to manoeuvre in the best way its resources allow. The challenge it faces is outlined in the following section.

\subsection{The Challenges Facing the DMO}

One of the biggest challenge that LADA faces is that it only has the power to monitor development on land that it owns. On private lands or lands belonging to other entity, LADA has very limited say as to how they should be developed. The main reason is the overlapping jurisdictions among multiple regulating agencies deter a more collaborative, unanimous goal among all stakeholders (Kasim and Dzakiria, 2015). Consequently, there are several patches of areas where development do not comply with the island's sustainable development aspiration. However, land ownership and power jurisdiction issues prevent LADA from getting involved.

Another challenge is the uncertainty in the commitment and efforts of relevant stakeholders towards the development guidelines provided in the Langkawi Tourism Blueprint. Some development projects can be observed to be incompatible with the sustainability notion. An example would be the blocking of Chenang Beach from public access by unregulated private development of accommodations and shops on the beach side. Lack of a proper sewerage treatment facility for this area also threatens the attractiveness of the beach with possible water pollution.

The complexity of engaging the stakeholders stems from a combination of factors. As previously mentioned, LADA is not the sole or leading government agency entrusted to govern Langkawi. There are many other local authorities such as Langkawi Municipality, Kedah State Government, the Federal Government and Tourism Malaysia. Consequently, there are simply too many strategies that have been mooted at various levels as to how Langkawi should be governed. Often, the adoption of these strategies do not fall through due to issues such as profiteering tendencies, concern over the effect of environmentally friendly measures on quality of service and tourist satisfaction, and frequent change of strategy or policy at the federal level.

"Our biggest challenge is that there is just too many strategies due to frequent change or strategy or policy at the federal level... follow through is sometimes lacking or incomplete within the cycle...Standards are sometimes secondary to profit and tourist satisfaction..".

\section{LADA Representative:}

A prevailing example is the Langkawi taxi service, which act as an important transportation provider to complete transportation service available in Langkawi. Taxis get transport tourists from the point of arrival to their intended place of stay in Langkawi, and take them back to the point of departure upon completion of their visit. Some of the taxi drivers are registered under Langkawi Taxi Association and some are just members of "Koperasi Teksi Langkawi". Taxi is the best option of getting around in Langkawi due to the number of taxi providers available. The taxi drivers are an essential contributor to Langkawi's tourism industry because their good service can attract more tourists to Langkawi. As tourism frontliners, they will be the first person to meet and greet newly arriving tourists. A friendly taxi service goes a long way in building customer relationship, which may contribute to repeat visit to Langkawi. The fare system for taxi service in Langkawi is different from taxi services in other cities such as Penang and Kuala Lumpur where fares are charged according to distance. In Langkawi, the taxi fares are fixed for every main point of attractions on the island. Tourists who want to use the taxi service need to buy the taxi fare ticket. This system is similar to a public bus system as Langkawi does not have a public bus service.

The managerial challenge in relation to tourist satisfaction relates to the challenge of collaboration between LADA and Langkawi taxi service. LADA claimed to have engaged in providing courses and workshops numerous times to improve taxi service in Langkawi and increase tourist satisfaction when utilizing this service. The trainings and workshops focused on building a good image of Langkawi's taxi service particularly in terms of new uniform attire for taxi drivers, new colour of taxi car, and the uniform in taxi fare, new management system and others. However most courses that LADA provide did not get the attention and active participation from the taxi service providers. 
From the taxi providers' perspectives, they felt that LADA does not really understand their main struggle, which is to survive in the midst of the rapid growth of car rental agencies on the island. They claimed they are struggling against the competition and have suffered from dwindling number of customers, as less and less tourists prefer taxis to rental cars. The presence of unregistered rental cars made things worse for taxi providers. It negatively affected the income of taxi drivers on a daily basis. According to a representative, more than 80 percent of taxi members were below the poverty line with an average monthly income of RM1,000. The representative attributed taxi drivers low income partly to the existence of about 4,000 unregistered rental cars on the island.

Consequently, there was a continuous difficulty for collaboration between LADA and taxi providers. On the one hand, taxi providers' reluctance to improve their image was considered as unwillingness to understand and embrace a plan to improve tourist satisfaction when visiting the island. On the other, failure of the authority to see the actual problems of taxi drivers was seen as an effort to 'address only the symptoms' rather than the problem. Considering that most of the taxi drivers were from the local community, the failure to address the taxi drivers was also seen as lack of empathy towards the local community within the island. They have had to take second jobs to supplement their small income. With the increase costs of living in Langkawi, things only got worse for the taxi service providers. The situation continued like a vicious cycle. Overworking made taxi drivers unable to focus on issues of good image and tourist satisfaction. Consequently less and less tourists preferred taxis or chose taxis as their mode of transportation when visiting Langkawi, the taxi drivers lost more income and became poorer in the midst of Langkawi's tourism growth.

In short, much work is required to change local business attitudes and understanding on service quality, tourist satisfaction and the importance of providing a safe, secure and generally pleasant travel experience to tourists. The effort should not stop at taxi drivers only because tourist satisfaction is the responsibility of all relevant authorities, tourism providers and even the local people. Tourist satisfaction could be enhanced by consistent improvement of amenities, ensuring continuous research to better understand important market segments and regulating businesses to ensure compliance of standards. The challenge is to not engage in attempt to satisfy all tourists, but to focus on a few important lucrative segments only. Another challenge is ensuring compliance of businesses because even though Langkawi does not lack rules and regulations for businesses, implementing those rules and regulations is challenging due to political pressure and outside interference by people with vested interests.

LADA also faces several managerial challenges in dealing with the local community, NGOs, and other government sector. Differing opinions and priorities among all involved is a situation that cannot be avoided when certain new development in Langkawi was implemented.

"Everyone wants to give their own opinion and idea regarding some issue so as a result no collaboration can be agreed upon".

\section{LADA Representative:}

"There is massive efforts and allocation to promote Langkawi..But we have too many tag line that none of them seem to be successful (in drawing tourists to Langkawi). Even the Naturally Langkawi tag line is not catching up (to expectation). There are just too many segments to focus".

\section{Private Sector Representative:}

One of the issues involved the community-based boat operators who are reluctant to participate in training programmes to improve their service quality especially from the aspect of safety. The operators feel that they 'know how to handle their business' better than LADA does. Almost 50\% of the boat operators dropped out of the training workshops after the first week. They also refuse to participate in voluntary activities organized by LADA. In addition, LADA also faced challenges in dealing with the hotel sectors, which refuse to participate with LADA by maintaining high pricing for passengers of chartered flights that LADA brings into Langkawi. Hotels also do not honour the promotional rate promised in the brochures that LADA use for their international promotion. LADA attributes this to greed that is killing any win-win collaboration that they currently have. There was also distrust between the private sector and LADA. While LADA often laments the lack of private sectors' participation in their events, the private sector voices distrust on the effectiveness of LADA's sustainable development effort: 
Application of corporate Social Responsibility in Stakeholder Management: The Case of Langkawi, Malaysia

"if LADA have new program for us, we don't want to join it. We don't trust (them) because many (of LADA's) past programmes failed".

\section{Private Sector Representative.}

One example given by the private sector is the use of unsuitable boats to enter the mangrove area during one of the volunteering programme that LADA organized. The private sector was unhappy with this because in their view, the use of unsuitable boats has negatively affected the mangrove area ecology and indirectly affected their ability to make an income from their Mangrove River Safari Tour package. Clearly LADA needs to take initiative to overcome such distrust if they want better collaboration from the private sector. Another example given relate to the issue of increasing illegal travel agents near Pantai Cenang. To this, LADA responded that they do not have the authority to sue and penalize them it is because the land on which they operate is their private property. In addition, there are political factors influencing such activities, which make it harder for LADA to address the problem. The fear of 'adding sand to someone's rice bowl' syndrome is prevalent. While this approach may be good in stimulating the local economy (from the activities of small and medium entrepreneurs), there is also the issue of tourist safety from such an unregulated activity.

The private sector is also unhappy with development of more five star hotels and theme parks on the island as this would only promote economic leakage. LADA is of different opinion on the matter because they insist that such project will hire local architect. The private sector representative doubted this statement and insisted that such constructions projects tend to hire foreign workers. Even after construction is completed, the lure of low paying foreign workers would make the project owners hire them to work in the hotel/theme park. The only way local community can participate is if they are allowed to open small businesses near the hotel/theme park.

Another managerial challenge is the assurance of tourist satisfaction via quality service from the private tourism providers. One example is the introduction of a Duck Boat tour at Oriental Village Langkawi. The tour was popular in the beginning due to the novelty of such experience particularly among local tourists. However, it lacks an important quality enhancing features i.e. tour interpretation either by tour guide or tour recording. As a consequence, tourists generally did not enjoy or found the tour meaningful for them. With time, lesser tourists wanted to take this tour and the Duck Boat tour becomes an unattractive tourism product in Langkawi. This example illustrates the tendency to offer tourism products and services that are seen as successful in other (international) tourism destinations without fully understanding tourist behaviours, needs and wants. Many other tourism products in Langkawi have suffered the same fate as the Duck Boat tour in the past for similar reason.

In relation to new tourism products that quickly become unattractive due to the lack of 'wow factor', LADA's stance is that they cannot monitor or impose standards on the private sector as this will create uneasiness among the private sectors. There is a great culturally influenced tendency to "not mess with others' rice pot'. This includes any activities conducted on private lands, or activities that are backed by politically influential individuals.

\section{THE RECOMMENDATION - CSR APPROACH AS THE WAY FORWARD}

The above case study has demonstrated the complexity a DMO could face in the effort to develop a destination sustainably. There are many issues and stakeholders a DMO needs to consider in any attempt to understand the challenges of developing a sustainable destination. It is therefore proposed that the DMO should adopt the CSR approach to better manage its relationship with the stakeholders. In addition, it is also proposed that Langkawi's DMO should adopt the values mooted in CSR - a process where a corporation shows and develops its 'corporate culture' and social consciousness (Rupp et al., 2006) which will allow it to think more holisticllay i.e. not only in terms of economic impact, but also social and environmental impacts. It will develop a sense of commitment not only to the economic development but also for social development and environmental sustainability. CSR helps to initiate a silent agreement between the organization and the society (Werther and Chandler, 2011) to balance their operations with the concern of stakeholders which include employees, customers, suppliers and business partners, labour unions, local communities, non-governmental organizations (NGO) and governments (Polasek, 2010). If CSR practices in the business world help display the willingness of the business to show "good citizenship", and gives the business a competitive advantage (Ellemers et. al., 2011), it is argued that the same benefit can also accrue if 
DMOs use CSR approach in dealing with their stakeholders. For Langkawi, this approach is timely because as Belmonte (2013) stated in the UNICEF CSR publication, the Malaysian government has been actively supporting, promoting as well as placing an importance on CSR practices to be implemented in business operations. This shows that the Malaysian government focuses not only on the economic development but also on the importance of social development and environmental sustainability that contribute to long term sustainable development. Thus, the government would be supportive of its adminstrative wings's effort to place importance of CSR and practice CSR in their operations.

Using the CSR approach, a DMO can decide to focus on integrating social and environmental concerns in their operations and interaction with their stakeholders (the Commission of European Communities, 2001 as cited in Low, 2016). A destination manager should attempt to understand the issues highlighted by directly communicating with the stakeholders involved to see things from their perspective. In the case of Langkawi, it can be seen that while LADA employs many strategies to embrace sustainable development, trust between the DMO and its stakeholders appears to be a major issue. Without trust, getting stakeholders to willingly join any shared efforts (see Kasim and Dzakiria, 2015) would be an uphill battle. In order to establish trust, information quality and accessibility (see Waligo et al., 2013) must be paramount. Trust is one of the most important parts that enable the success of a smart partnership. It could reduce conflict in the planning stages, minimize negative impacts and maximize the benefits of the development for all stakeholders. However, trust among stakeholders cannot be forced, but must be obtained through action and trust can only be built through consistency and integrity of action over time. Betrayal can destroy the trust that has been built over a long time and it will be difficult to regain the same level of trust among the stakeholders involved. Some things will arouse suspicion of the motives of people, or act in any way contrary to the interests of the smart partnership which is at the expense of others for their own benefit, not respecting the views or ideas of others, there is a commitment to something and confidentiality. Trust will enhance a positive mindset among the stakeholders and enable them to grasp their involvement capacity. To create trust, stakeholder relationships must be positive and this can be established by adhering to Gray's (1989) proposal to deal constructively with the parties involved, and to create a sense of joint ownership of all decisions made.

The quality of stakeholder relationship that Walingo et al. (2014) proposed will also determine the level of patience and tolerance involved. Patience and tolerance are critical factors for successful smart partnership. It needs focus on new ideas, willingness to listen to the views of partners and the ability to respect the differences that each of them brings to the coalition are of utmost importance in improving collaboration. The voice of all its members must be heard and given full consideration prior to any important decision-making. Sometimes, the dominant partner has to postpone certain decisions when no consensus has been reached so as to preserve the partnership. Successful partnerships begin and grow with a clear understanding that mutual benefits will be distributed to partners involved. Each partner may not benefit equally, but each one must be aware of the benefits of value added. Without concrete results, the continued commitment to the partnership is unlikely it will be successful. Without real benefits, no one is going to sacrifice the time, energy and money to maintain the partnership in stakeholder. In the Malaysian context, the benefits of continued economic growth and the equitable sharing of the growing economy chart provide motivation for continued support consensus -based framework for political partnership.

As DMOs are essentially leaders of a destination's development, they are responsible for coordinating and planning sustainable policies and practices that would involve all of the destination's stakeholders. As such their roles can be akin to that of an office boss who has to deal with various staff members. Keeping this analogy in mind, then they can use CSR approach to influence the stakeholders just as well as a boss could to influence his/her staff members. According to Chua et al.'s (2011) study on the employees' perception on organizational commitment towards the internal CSR practices of the organization which focused on health and safety, work life balance policy, training and development, employee autonomy as well as compensation and benefits in Malaysia, the employees perceive these dimensions as important towards organizational commitment. As Ummu Asma Musa and Azmawani Abd Rahman (2015) study has concluded, a positive perception can lead to employees' attachment towards their job. This finding has been supported by Hsieh and Chan (2012) who studied on the employees of Taiwan Securities Exchange (TSE), Lee et al.'s (2009) study which focused on the employees in the manufacturing companies in Taiwan and by Zam Zuryati 
Mohamad et al. (2013) also studied on the employees' perception towards CSR on organizational commitment in the hotel industry in Penang, Malaysia. That means that meeting stakeholders' expectations towards CSR are important. Hence, DMOs who focused on CSR attributes in their destination (such as ethics, safety, balance, development, autonomy and reward) could also benefit from a more committed stakeholders because stakeholders who are positive and happy would invest more of their time in support of the DMOs' initiatives.

As CSR approach also promotes a balanced and sustainable initiative, Langkawi's effort to engage with the stakeholders can be further improved by taking the following recommended strategies i.e. 1 . Inculcating smart partnerships; and 2. Upgrading the community's livelihood by making Langkawi one of the top ten tourism destinations in the world. Smart partnership refers to the concept of maximizing and balancing the benefits for both parties and for all, regardless of an unequal contribution towards the partnership. The concept has been introduced in 1995, at the First Langkawi International Dialogue (LID) held in Malaysia (LADA, 1999). This concept is taken from the win-win situation using policies that are guided by common values of trust, good faith, understanding, respect and fair. A good environmental management can have an impact on win-win situation; human wellbeing is closely related to environmental conditions (Kareiva, Tallis, Ricketts, Daily, and Polasky, 2011).

Win - win approach aims to build a strong foundation for continued peace and prosperity based on shared interests and shared values that emphasize on economic cooperation, social and cultural rights. Smart partnership of stakeholders in the context of the development of tourism in Langkawi also means all parties have the same rights or unfair advantage. Such low power distance situation (Ahmad et al., 2014) is not something that is enshrined in policy and procedure but depends on the level of formality of a relationship and mutual understanding of the benefits involved. a clear understanding of the strengths and limitations of each of the stakeholders involved, trust in carrying out the task, willingness to compromise, patience and a high level of tolerance and finally be able to achieve a good result as an value added in a joint ventures. A successful stakeholder partnership it is also important for partners to have a clear of the strengths and limitations of each section. It helps partners to develop more realistic expectations of the potential and their contribution while minimizing the possibility of unreasonable demands. The strengths and weaknesses of partners, special programs can be developed to accelerate the development process and reduce the gap between them. For example "Public Education in Heritage Conservation for Geopark Community" held by LADA at Langkawi.

Upgrading the livelihood of the people is another strategy. It can create positive motivation among all stakeholders (Jakše and Ambrož, 2015) involved to do more and better. Motivated stakeholders are more likely to deal constructively with differences, feel joint ownership of decisions made and share any responsibility that might emerge (see Kasim and Dzakiria, 2015). If tourism has proven to be successful in upgrading people's livelihood from traditional economies in the $80 \mathrm{~s}$, then more effort needs to be taken to address more current issues such as low income employment, rising prices for locals, crimes and the influx of foreign workers to replace local workers in the industry. However, these efforts also require direct and clear communication, along with devising ways to collaborate and partner in mutually benefitting activities to attain all objectives laid out in the Langkawi Blueprint. More research/reading is also required to better understand the applied side of principles of sustainable development especially as they apply to Langkawi, so that the managers can impart this useful environmental knowledge onto the less knowledgeable stakeholders especially the village community and the businesses and convince them of the importance of sustainable tourism as the way forward for Langkawi tourism.

In conclusion, the complexity of managing a tourism destination makes it essential for destination managers to form collaborative coping mechanisms. This is a complex task due to the fragmented and diverse nature of tourism stakeholders with equally fragmented and diverse view on tourism resource management. It requires successful collaborative effort and partnership between destination managers, businesses, the local community and others with interest on the same issue. In other words, destination management organizations need to identify their stakeholders and make effort to collaborate with them. In developing a sustainable tourism destination such as Langkawi, identifying the key stakeholders in the implementation process would ensure a clear segregation of responsibilities and avoid redundancy of roles. For example, government agencies, industry bodies, 
educational institutions and NGO can focus on the provision and maintenance of the tourism infrastructure, on determining the educational and training system, on setting rules for business operations, on assisting in financing and on conducting both research and market promotion. The local communities and the local host organizations can stimulus and share control over development initiatives and the decisions. More importantly, the role of business in sustainable development has to be clearly spelled out. Concepts of corporate social responsibility and responsible business have been proposed to engage with businesses and enhance their awareness about their important role towards the community and environment within which they operate.

\section{REFERENCES}

[1] Abdullah, N., Hassan, H., Ali, M., and Ab. Karim, M. (2014). Cultural values (power distance) impact on the stakeholders' engagement in organizing the Monsoon Cup international sailing event. Procedia - Social and Behavioral Sciences , 118 - 126.

[2] Anuar, A.N. A., Ahmad, H., Jusoh, H., and Hussain, M.Y. (2013), Policy and tourism development strategy towards tourist friendly destination in Kuala Lumpur, Asian Social Science, 9 (2): 180-190.

[3] Belmonte, W. (2013). Corporate Social Responsibility Policies In Malaysia - Enhancing the child focus. Malaysia: UNICEF.

[4] Bernama (2010, December 8). Tourist Arrivals to Malaysia have Grown Drastically: Yen Yen. Bernama

[5] Chua, K. M., Koay, S. M, Leng, S. M, Ng, P. F. and Tan, S. T. (2011). Employees' Perception On Organizational Commitment In Corporate Social Responsibility (Bachelor's thesis, Universiti Tunku Abdul Rahman). Retrieved from http://eprints.utar.edu.my/689/1/BA-20110901027.pdf

[6] Corporate social responsibility. (n.d). In Investopedia. Retrieved May 12, 2016, from http://www.investopedia.com/terms/c/corp-social-responsibility.asp

[7] Ellemers, N., Kingma, L., Van de Burgt, J. and Barreto, M. (2011). Corporate Social Responsibility as A Source Of Organizational Morality, Employee Commitment And Satisfaction. Journal of Organizational Moral Psychology, 1(2), 97-124.

[8] European Commission. (2001). GREEN PAPER : Promoting a European framework for Corporate Social Responsibility. Paper presented by the commission, Brussel, 18 July.

[9] Government of Malaysia (GOM) Seventh Malaysia Plan 1996-2000. Kuala Lumpur: Percetakan Nasional Malaysia Berhad.

[10] Gray, B. (1989), Collaborating: Finding Common Ground for Multiparty Problems, San Francisco: Jossey-Bass.

[11] Hsieh, Y. H. and Chan, J. Y. (2012). Corporate Social Responsibility: A concern among employees. Human Systems Management, 31(2012), 219-230.

[12] http://www.academia.edu/1150230/RELATIONSHIPS_BETWEEN_EMPLOYEESPERCEPTI ON_OF_CORPORATE_SOCIAL_RESPONSIBILITY_PERSONALITY_JOB_SATISFACTIO N_AND_

[13] International Finance Corporation World Bank Group (2007). Stakeholder Engagement: A Good Practice Handbook for Companies Doing Business in Emerging Markets. Retrieved November 2015, from International Finance Corporation World Bank Group: http://www.ifc.org

[14] Jakše, L.-M., and Ambrož, M. (2015). Actor-Network Theory and Stakeholder Collaboration: The Case of Slovenia. Mediterranean Journal of Social Sciences, Vol 6 No 3 S2.

[15] Johnsen, J. (2013). Travelling to Prosperity : A look into the inclusionary transformation process of the Perhentian Island. Bachelor Thesis in Development Studies .

[16] Kareiva, P., Tallis, H., Ricketts, T., Daily, G., and Polasky, S. (2011). Natural Capital: Theory and Practice of Mapping Ecosystem Services. Oxford University Press.

[17] Kasim, A. (2006). The Need for Business Environmental and Social Responsibility in the Tourism Industry. International Journal of Hospitality and Tourism Administration, 7(1), 1-22.

[18] Kasim, A. and Dzakiria, H. (2015). Challenges of Collaborative Partnership in Developing a Sustainable Nature Based Tourism in Langkawi in Gursoy, D., Saayman, M. and Sotiriadis, M. 
(Eds.), Collaboration in Tourism Businesses and Destinations, A Handbook, Emerald Group Publishing Limited, Bingley, UK, pp.205-224, ISBN 9781783508112.

[19] LADA Annual Report. (2013). Kedah, Malaysia: Langkawi Development Authority (LADA).

[20] LADA. (1999). Kajian Kependudukan Sosio-ekonomi Pulau Langkawi. Kedah: Langkawi Development Authority (LADA).

[21] Langkawi Development Authority (LADA). (2015). Retrieved 2015, from Official Website Langkawi Development Authority (LADA): http://www.lada.gov.my

[22] Langkawi Municipal Council . (2015). Retrieved from Official Website Langkawi Municipal Council, The City of Tourism: http://www.mplbp.gov.my

[23] Langkawi Municipal Council. (2002). Langkawi Local Plan 2001-2015: Technical Report. Langkawi District Council Department of Town and Country Planning, Peninsular Malaysia.

[24] Lee, T. Z., Ho, M. H., Wu, C. H and Kao, S. C. (2009). Relationship Between Employees' Perception Of Corporate Social Responsibility, Personality, Job Satisfaction And Organizational Commitment. Retrieved from

[25] Low, M. P. (2016). Corporate Social Responsibility and the Evolution of Internal Corporate Social Responsibility in $21^{\text {st }}$ Century. Asian Journal of Social Sciences and Management Studies, 3(1), 56-74.

[26] Maiden, J. (2008). Participation in Sustainable Tourism Development:Stakeholders and Partnership Working. United States: ProQuest LLC 2013.

[27] Mainardes, E., Alves, H., and Raposo, M. (2012). A model for stakeholder classification and stakeholder relationships. Management Decision, Vol. 50 Iss 10 pp. 1861 - 1879.

[28] Marzuki, A. (2008). Impacts of Tourism Development in Langkawi Island, Malaysia: a Qualitative Approach. International Journal of Hospitality and Tourism Systems, Volume 1 Issue 1

[29] Monowar Mahmood and Humphrey, J. (2013). Stakeholder Expectation of Corporate Social Responsibility Practices: A Study on Local and Multinational Corporations in Kazakhstan. Corporate Social Responsibility and Environment Management, 20, 168-181.

[30] Performance Management and Delivery Unit (PEMANDU, 2012). Economic Transformation Programme: Annual report 2012.2 Retrieved from http://etp.pemandu.gov.my/annualreport/upload/Eng_ETP2012_Full.pdf

[31] Polasek, D. (2010). Corporate Social Responsibility in Small and Medium-Size Companies in the Czech Republic (Doctoral dissertation, Czech Management Institute, Czech Republic).

[32] Rupp, D. E., Ganapathi, J., Aguilera. R. V., and Williams, C. A. (2006). Employee reactions to corporate social responsibility: an organizational justice framework. Journal of Organizational Behaviour, 27, 537-543.

[33] Stoian, C. and Zaharia, R. M. (2012). CSR development in post-communist economies: Employees' expectation towards corporate social responsibility behaviour: The case of Romania.

[34] Tourism Malaysia website http://corporate.tourism.gov.my/research.asp?page=facts_figures

[35] Tuohino, A., and Konu, H. (2014). Local stakeholders' views about destination management: who are leading tourism development? Tourism Review, Vol. 69 Iss 3 pp. 202 - 215.

[36] Ummu Asma Musa and Azmawani Abd Rahman. (2015). Employee Perception of CSR Activities, Job Attachment and Organizational Commitment. Pertanika Journal of Social Sciences and Humanities, 23, 1-16.

[37] Waligo, Victoria, Clarke, Jackie, Hawkins, and Rebecca. (2013). Implementing sustainable tourism: a multi-stakeholder involvement management framework. Tourism Management, 342.353.

[38] Werther, W. B. and Chandler, D. (2011). Strategic Corporate Social Responsibility. California : SAGE Publication, Inc

[39] Yam, S. (2012). Corporate social responsibility and the Malaysian property industry.Paper presented at the 18th Annual PRRES Conference, Adelaide, Australia, 15-18 January. 
[40] Yilmaz, B., and Gunel, O. (2009). The Importance of Strategic Stakeholder Management in Tourism Sector: Research on Probable Applications. Tourismos: An International Multidisciplinary Journal of Tourism, Volume 4, 97-108.

[41] Yusniyati Yusri and Azlan Amran. (2012). CSR Towards Workplace And Human Resource Disclosure: Employees' Perspectives. Malaysian Accounting Review, Special Issue, 11(2), 39-68.

[42] Zam Zuriyati Mohamad, Khor, R. S., Ng, K. S., Ong, J. F. Poh, S. H. and Tang, K. K. (2013).Value Added of Corporate Social Responsibility On Organizational Commitment: An Employee's Perception. International Journal of Accounting and Business Management, 1(1), 92-98.

\section{APPENDIX}

\section{Letter of Authorization by LADA}

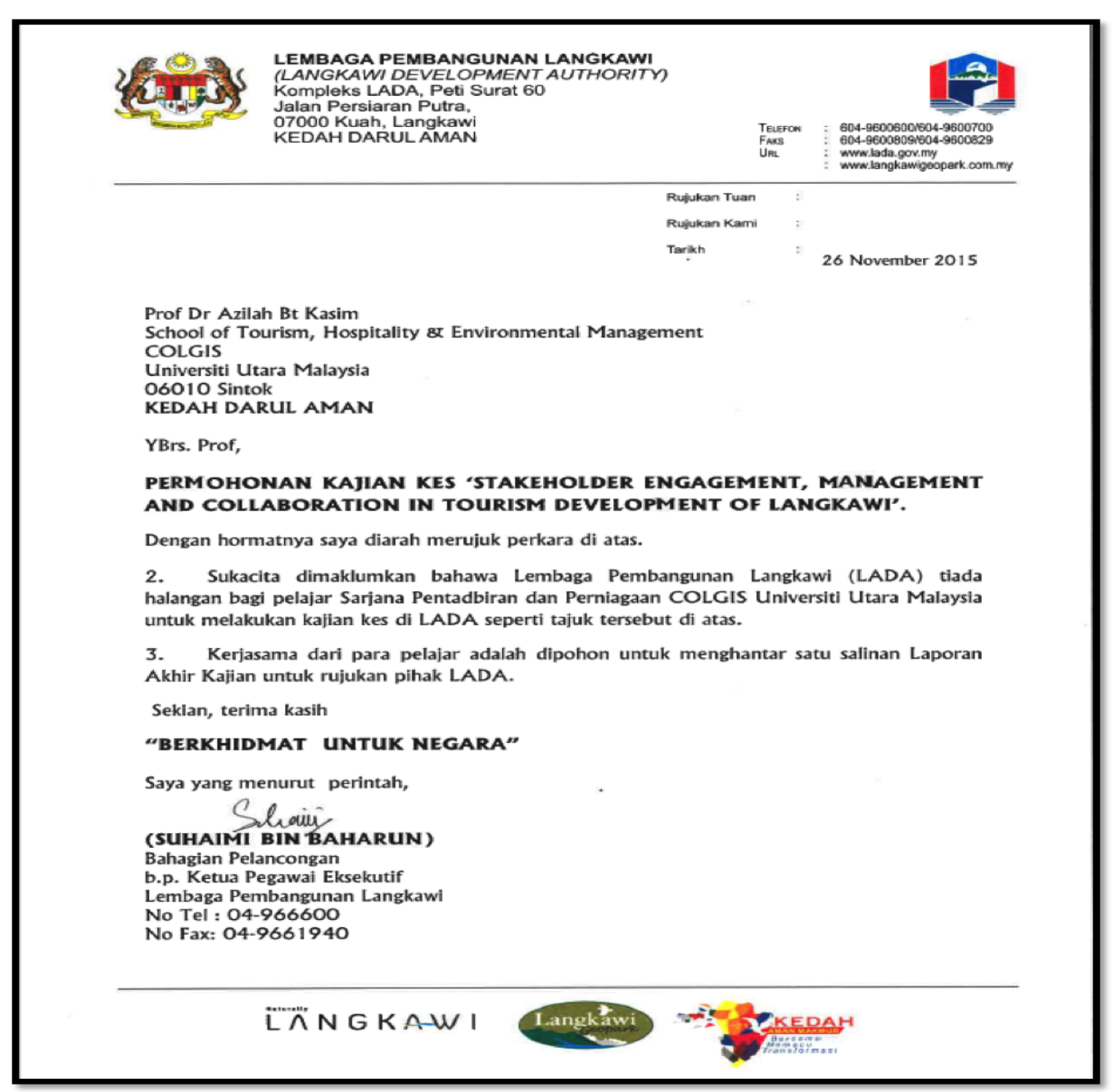

Citation: Azilah, Kasim et al. "Application of Corporate Social Responsibility in Stakeholder Management: The Case of Langkawi, Malaysia." International Journal of Research in Tourism and Hospitality (IJRTH), vol 3, no. 3, 2017, pp. 25-42. doi:http://dx.doi.org/10.20431/2455-0043.0303004.

Copyright: (0) 2017 Authors. This is an open-access article distributed under the terms of the Creative Commons Attribution License, which permits unrestricted use, distribution, and reproduction in any medium, provided the original author and source are credited. 